\title{
Divergência genética de cultivares de cana-de-açúcar quanto à resistência a Diatraea saccharalis ${ }^{1}$
}

\author{
Genetic divergence of sugar cane cultivars for resistance to \\ Diatraea saccharalis
}

\author{
Joseane Rodrigues de Souza ${ }^{2 *}$; Arlindo Leal Boiça Júnior ${ }^{3}$; Dilermando Perecin ${ }^{4}$; \\ Alberto Cargnelutti Filho ${ }^{5}$; Jacqueline Tonielo da Costa $^{6}$
}

\begin{abstract}
Resumo
O objetivo do trabalho foi avaliar a divergência genética de cultivares de cana-de-açúcar quanto à resistência a $D$. saccharalis. O experimento foi conduzido em laboratório em delineamento inteiramente casualizado, com 11 tratamentos (uma testemunha e dez cultivares) em dez repetições. As repetições foram constituídas a partir de dietas artificiais (alimentação e realimentação) elaboradas com colmo seco triturado de cada cultivar de cana-de-açúcar, com exceção de uma delas considerada dieta padrão. As cultivares utilizadas foram: RB867515, RB855453, RB855536, CTC 15, CTC 9, SP80-1842, SP791011, SP89-1115, SP81-3250 e SP87-365. Na avaliação foram consideradas as seguintes características biológicas do inseto: período larval (dias), viabilidade larval (\%), período pupal (dias), peso de pupas (g), viabilidade pupal (\%), período da eclosão da larva à emergência do adulto (dias), viabilidade total (\%) e a longevidade dos adultos de D. saccharalis sem alimento (dias). Determinou-se a distância generalizada de Mahalanobis $\left(\mathrm{D}^{2}\right)$ para a análise de agrupamento pelo método da ligação média entre grupo (UPGMA) e otimização de Tocher. Foram formados quatro e cinco grupos, respectivamente, pelo método da ligação média entre grupo (UPGMA) e otimização de Tocher. Conclui-se que a cultivar CTC 15 apresentou-se como altamente suscetível a $D$. saccharalis, enquanto a cultivar SP87-365 comportouse como moderadamente resistente do tipo antibiose a $D$. saccharalis.

Palavras-chave: Saccharum spp., resistência de plantas a insetos, broca-da-cana, análise multivariada
\end{abstract}

\begin{abstract}
The objective was to evaluate the genetic diversity of cultivars in sugar cane for resistance to $D$. saccharalis. The experiment was carried out in the laboratory in completely randomized design with 11 treatments (one control and 10 treatments) in ten replications. The replications were made from artificial diets (food and refood) made with dry steam crushed from sugar cane cultivars stems, except for one of them considered standard diet. The cultivars used were: RB867515, RB855453, RB855536, CTC 15, CTC 9, SP80-1842, SP79-1011, SP89-1115, SP81-3250 and SP87-365. In the evaluation biological characteristics of the insect considered were: larval development (days), larval viability (\%), pupal
\end{abstract}

\footnotetext{
${ }^{1}$ Parte da Tese de Doutorado do primeiro autor. Programa de Produção Vegetal, Universidade Estadual Paulista, Faculdade de Ciências Agrárias e Veterinárias, FCAV/UNESP, Jaboticabal, SP.

${ }^{2}$ Eng $^{\mathrm{a}}$ Agra ${ }^{\mathrm{a}}$, Pesquisadora de Desenvolvimento Cientifico Regional da Universidade Federal do Maranhão, UFMA Bolsista FAPEMA/CNPq, Chapadinha, MA. E-mail: joseaneagro@yahoo.com.br

${ }^{3}$ Eng $^{\circ}$ Agr $^{\circ}$, Dr. Prof. do Dept ${ }^{\circ}$ de Fitossanidade, FCAV/UNESP, Jaboticabal, SP. E-mail: aboicajr@fcav.unesp.br

${ }^{4}$ Eng $^{\mathrm{o}} \mathrm{Agr}^{\circ}$, Dr. Prof. do Dept ${ }^{\mathrm{o}}$ de Ciências Exatas, FCAV/UNESP, Jaboticabal, SP. E-mail: perecin@fcav.unesp.br

${ }^{5}$ Eng $^{\mathrm{o}}$ Agr $^{\circ}$, Dr. Prof. do Dept ${ }^{\mathrm{o}}$ de Fitotecnia, Universidade Federal de Santa Maria, UFSM, Santa Maria, RS. E-mail: cargnelutti@ ufrgs.br

${ }^{6}$ Eng $^{\mathrm{a}}$ Agr $^{\mathrm{a}}$, Discente de Doutorado do Dept ${ }^{\mathrm{o}}$ de Solos e Adubos, FCAV/UNESP, Jaboticabal, SP. E-mail: jacquelinetonielo@ yahoo.com.br

* Autor para correspondência
} 
development (days), pupal weight (g), pupal viability (\%), period of hatched larvae to adults emergence (days), total viability (\%) and adults longevity without food (days). The generalized Mahalanobis distance $\left(\mathrm{D}^{2}\right)$ for the cluster analysis by the method of average linkage between groups (UPGMA) and Tocher's method optimization was determined. Four and five groups were formed, respectively, by the method of average linkage between groups (UPGMA) and Tocher's method optimization. We concluded that the cultivar CTC 15 standed out as highly susceptible to D. saccharalis, while the cultivar SP87365 behaved as moderately resistant by antibiosis to $D$. saccharalis.

Key words: Saccharum spp., host-plant insect resistance, sugar cane borer, multivariate analysis

\section{Introdução}

O Brasil é o maior produtor mundial de canade-açúcar (Saccharum spp.) e responsável por aproximadamente 708 milhões de toneladas para a safra 2011/2012 (AGRIANUAL, 2010). A produtividade de cana-de-açúcar depende da qualidade da muda e da cultivar, do ambiente e manejo do solo e do controle de insetos-praga (SCAGLIA et al., 2005). Entre as diversas pragas que atacam a cultura no Brasil, a broca da cana, Diatraea saccharalis (Fabricius, 1794) (Lepidoptera: Crambidae), é a espécie de maior relevância nos canaviais brasileiros (DINARDOMIRANDA, 2008), por sua ampla distribuição (MACEDO; ARAÚJO, 2000) e a que causa os maiores prejuízos para a cultura (SCAGLIA et al., 2005).

As lagartas de D. saccharalis ao se alimentarem da cana-de-açúcar podem ocasionar danos diretos que se caracterizam por: perda de peso (pela abertura de galerias no entrenó), perfilhamento, enraizamento aéreo, brotação das gemas laterais e morte da gema apical da planta ("coração morto") e danos indiretos, sendo estes consideráveis e causados pelos fungos Fusarium moniliforme e Colletotrichum falcatum que provocam a "podridão vermelha" do colmo, ocasionando a inversão da sacarose, diminuindo a pureza do caldo resultando em menor rendimento de açúcar e álcool (GALLO et al., 2002, DINARDO-MIRANDA, 2008, PINTO; BOTELHO; OLIVEIRA, 2009).

Entre os métodos de controle de D. saccharalis em cana-de-açúcar destaca-se a utilização de cultivares resistentes. Para White (1993), a utilização de cultivares de cana-de-açúcar resistentes a $D$. saccharalis é importante no seu controle. Os benefícios potenciais que podem advir da utilização de cultivares resistentes foi relatado por Lara (1991), sendo considerado um método ideal, uma vez que as populações das pragas podem ser mantidas abaixo de seus níveis de danos, reduz a contaminação dos agroecossistemas mediante o não uso abusivo de agroquímicos, não exigem conhecimentos específicos do agricultor e nem custos adicionais.

Nos programas de melhoramento de cana-deaçúcar, fontes de resistência a $D$. saccaharalis presentes em cultivares de Saccharum spp., podem ser introduzidas em cultivares de cana que apresentem todas as características agronômicas favoráveis e que não possua resistência a broca da cana. Existem poucos trabalhos na literatura brasileira que tratam da resistência de cultivares de cana-de-açúcar a $D$. saccharalis, especialmente aqueles conduzidos com as cultivares comerciais antigas. Mais recentemente, Demetrio, Zonetti e Munhoz (2008) selecionaram, entre dez clones RB's série 97, os clones RB975311 e RB9755286 como portadores de resistência a $D$. saccharalis por apresentarem menor ocorrência de ataque a referida praga, média de $1,7 \%$ e 3,5\% de infestação, respectivamente, além de boa produtividade e qualidade tecnológica.

Além do conhecimento de cultivares portadoras de resistência a $D$. saccharalis, outro fator importante, visando à obtenção de cultivar resistente a esse inseto, é o estudo da divergência genética. Neste, o grau de dissimilaridade entre os indivíduos dentro ou entre espécies, ou entre genótipos dentro de uma população melhorada, pode ser estimado 
por meio de técnicas multivariadas, como a análise de agrupamento (CRUZ; REGAZZI, 1997).

Dessa forma, estudos que visam à busca de cultivares resistentes a $D$. saccharalis são de suma importância para o setor sucroalcooleiro, nos aspectos de redução de custos e no desenvolvimento da cultura da cana-de-açúcar, aspectos estes que resultarão em maior economia e longevidade das cultivares (DEMETRIO; ZONETTI; MUNHOZ, 2008).

Portanto, objetivou-se avaliar a divergência genética de cultivares de cana-de-açúcar quanto à resistência a $D$. saccharalis.

\section{Material e Métodos}

O experimento foi realizado em laboratório no período de setembro a novembro de 2010 . Foram elaboradas dietas artificiais (alimentação e realimentação) segundo a metodologia de Hensley e Hammond (1968), modificada por Araújo et al. (1985), sendo incorporado às dietas colmo seco triturado de cada cultivar de cana-de-açúcar, com exceção de uma delas que não recebeu a adição de colmos e foi considerada dieta padrão (BOIÇA JUNIOR et al., 1997, 2011).

As cultivares utilizadas foram: RB867515, RB855453, RB855536, CTC 15, CTC 9, SP80-1842, SP79-1011, SP89-1115, SP81-3250 e SP87-365 cedidas pela Cooperativa dos Produtores de Cana do Oeste do Estado de São Paulo\COPERCANA, localizada no município de Sertãozinho (SP), enquanto as lagartas de $D$. saccharalis foram fornecidas pela Usina São Martinho, localizada no município de Pradópolis, SP.

Inicialmente, toletes das dez cultivares foram plantados em setembro de 2009, em solo do tipo Latossolo Vermelho eutroférrico (LVef) textura muito argilosa a moderado (EMBRAPA, 1999) visando à obtenção de colmos. Foi plantada uma linha de $15 \mathrm{~m}$ de cada cultivar espaçada a $0,5 \mathrm{~m}$ no sulco de plantio. A adubação para a cultura da cana-de-açúcar foi realizada de acordo com as recomendações de Rossetto, Dias e Vitti (2008) e os tratos culturais segundo Xavier et al. (2008).

Quando as plantas atingiram 13 meses de idade os colmos de cada cultivar foram coletados e levados para o laboratório onde se retirou a parte central de cada colmo. Em seguida, estes foram cortados e colocados em estufa a $60^{\circ} \mathrm{C}$ por 48 horas. Após a secagem, a parte central do colmo de cada cultivar foi triturada em moinho de facas modelo Willey TE-650, sendo em seguida pesados 40,0 g de cada cultivar que foram incorporadas às dietas artificiais. No momento da preparação da dieta de alimentação e realimentação, adicionaram-se 1000 e 666,66 mL de água fervida, respectivamente, para a dissolução do caragenato, sendo paralelamente adicionados 666,66 mL de água aos ingredientes sólidos e líquidos.

A dieta de alimentação foi preparada e utilizada até as lagartas de D. saccharalis atingirem 19 dias de idade após a inoculação. Após o preparo da dieta de alimentação, a mesma foi colocada no interior de dez tubos de vidro para cada cultivar. Em seguida, foram inoculadas com o auxílio de um pincel em cada tubo 20 lagartas de $D$. saccharalis recém-eclodidas. Posteriormente, os tubos foram tamponados com chumaços de algodão hidrófobo e mantidos em grades metálicas na posição vertical a temperatura de $28 \pm 1{ }^{\circ} \mathrm{C}$, umidade relativa de $80 \pm$ $10 \%$ e fotofase de 14 horas.

O delineamento experimental utilizado foi inteiramente casualizado, com 11 tratamentos em dez repetições. As repetições foram constituídas por tubos de vidro de $8,5 \mathrm{~cm}$ de altura $\mathrm{x} 2,5 \mathrm{~cm}$ de diâmetro.

Quando as lagartas de D. saccharalis atingiram 19 dias de idade, após a inoculação, foi preparada a dieta de realimentação, sendo a mesma cortada em forma de cubos e oferecida às lagartas sendo estas alimentadas até atingirem a fase de pupa. As lagartas de $D$. saccharalis foram retiradas dos tubos e colocadas em placas de Petri de $12 \mathrm{~cm}$ de diâmetro x $2 \mathrm{~cm}$ de altura, contendo em seu interior cubos 
de dieta de realimentação e mantidas nas mesmas condições dos tubos. As pupas foram separadas por data de pupação e alojadas individualmente em copos descartáveis de $100 \mathrm{~mL}$ com $9 \mathrm{~cm}$ de diâmetro x $2 \mathrm{~cm}$ de altura forrados com papel filtro até a emergência dos adultos.

Foram avaliadas as seguintes características biológicas: durante a fase larval do inseto foi avaliada diariamente a duração do período em dias e a partir desse calculada a viabilidade em porcentagem. Quando ocorreu a pupação que também foi observada diariamente, calculou-se a duração desse período em dias, e a partir desse determinou-se a viabilidade em \%, além do peso de pupas com 24 horas de idade, em gramas (g). Por ocasião da emergência dos adultos, avaliou-se a duração do período da eclosão da larva à emergência do adulto (PELEA) em dias, a viabilidade total em porcentagem e a longevidade dos adultos de $D$. saccharalis sem alimento.

Os dados obtidos foram submetidos à análise de variância pelo teste $\mathrm{F}$ e as médias comparadas pelo teste de Tukey a 5\% de significância. Determinou-se a distância generalizada de Mahalanobis $\left(\mathrm{D}^{2}\right)$ para a análise de agrupamento da testemunha e cultivares pelo método da ligação média entre grupo(UPGMA) e otimização de Tocher. Calculou-se o coeficiente de correlação cofenética (CCC) para verificar o ajuste entre a matriz de dissimilaridade e o dendrograma obtido pelo método da ligação média entre grupo (UPGMA) e valores próximos à unidade indicam melhor representação (CRUZ; CARNEIRO, 2003). Para afirmar se os procedimentos multivariados foram eficientes realizou-se a validação dos grupos por meio do perfil das médias das características biológicas obtidas para cada um dos grupos.

As análises estatísticas foram realizadas no Office Excel e no programa Genes (CRUZ, 2006).

\section{Resultados e Discussão}

O sistema utilizado foi adequado já que todas as dietas artificiais apresentaram características nutricionais possibilitando às larvas a aquisição do alimento e, posteriormente, desenvolvimento até a fase adulta.

Houve diferença significativa entre os tratamentos para as características biológicas período larval, viabilidade larval, período pupal, período da eclosão da larva à emergência do adulto, viabilidade total e longevidade dos adultos (Tabela 1) indicando a existência de variabilidade genética entre as cultivares e a possibilidade de agrupálas por técnicas de análise multivariada (CRUZ; REGAZZI; CARNEIRO, 2004). O período larval de $D$. saccharalis na testemunha foi o mais longo (27,5 dias), entretanto esse valor foi ligeiramente próximo aos observados nas cultivares CTC 9, SP79-1011, SP87-365, SP80-1842 e RB855536, que ficaram em posição intermediária e apresentaram, respectivamente, 26,$5 ; 26,5 ; 26,4 ; 26,3$; e 26,2 dias enquanto as demais cultivares SP81-3250, SP89-1115, RB855453, CTC 15 e RB867515 foram as mais adequadas para a alimentação de D. saccharalis (Tabela 1). O alongamento do período larval pode ser atribuído à diferença na constituição da dieta artificial, devido à presença de colmo seco triturado de cada cultivar, pois de acordo com Silveira, Vendramim e Rossetto (1997), o alongamento do referido período é um indicativo de menor adequação do substrato alimentar.

Boiça Junior et al. (2011) demonstraram efeitos adversos na biologia de $D$. saccharalis entre cultivares de cana-de-açúcar com a incorporação de colmo seco triturado em dieta artificial, sendo a duração do período larval de 28,8 dias. A duração do período larval de $D$. saccharalis também foi verificada por Boiça Junior et al. (1997) em dieta artificial com a incorporação de colmos das cultivares SP71-1081 e SP 71-3146, consideradas, respectivamente, moderadamente resistente $\mathrm{e}$ suscetível à broca da cana. De acordo com os autores, a duração do período larval foi de 27,9 dias e de 26,8 dias, respectivamente. Nesse caso, concluiu-se que as cultivares que determinaram um alongamento do período larval possivelmente apresentam algum 
fator de resistência a $D$. saccharalis, pois foram menos adequadas para a alimentação das lagartas. No presente estudo, a maioria das cultivares foram semelhantes à testemunha no que refere à duração do período larval.

A viabilidade larval variou de 75,0 a $95,8 \%$ sendo registrado o menor valor na cultivar SP87365 o maior na cultivar CTC 15 ficando as demais cultivares em posição intermediária (Tabela 1). Esses resultados sugerem que a cultivar CTC
15 comportou-se como a mais suscetível a $D$. saccharalis e a SP87-365 com resistência do tipo antibiose, pois demonstrou ser menos favorável ao desenvolvimento das larvas. De acordo com Lara (1991) a mortalidade das formas jovens, criadas sobre plantas resistentes é frequentemente observada durante os primeiros instares do inseto, e talvez seja a característica biológica mais indicativa da ocorrência de resistência do tipo antibiose aliada ao tamanho e ao peso dos insetos.

Tabela 1. Período larval (dias), viabilidade larval (\%), período pupal (dias), peso de pupas (g), viabilidade pupal (\%), período da eclosão da larva à emergência do adulto (PELEA) (dias), viabilidade total (\%) e longevidade de adultos (dias) de Diatraea saccharalis, alimentadas em uma dieta artificial padrão (testemunha) e dez composta por colmo seco triturado de dez cultivares de cana-de-açúcar. Temperatura: $28 \pm 1{ }^{\circ} \mathrm{C}$; Umidade relativa: $80 \pm 10 \%$; Fotofase: 14 horas.

\begin{tabular}{|c|c|c|c|c|c|c|c|c|}
\hline \multirow[b]{2}{*}{ Tratamentos } & \multicolumn{2}{|c|}{ Fase larval } & \multicolumn{3}{|c|}{ Fase pupal } & \multirow[b]{2}{*}{$\begin{array}{c}\text { PELEA } \\
\text { (dias) }\end{array}$} & \multirow[b]{2}{*}{$\begin{array}{c}\text { Viabilidade } \\
\text { total } \\
(\%)\end{array}$} & \multirow[b]{2}{*}{$\begin{array}{l}\text { Longevidade } \\
\text { (dias) }\end{array}$} \\
\hline & $\begin{array}{l}\text { Duração } \\
\text { (dias) }\end{array}$ & $\begin{array}{c}\text { Viabilidade } \\
\text { larval } \\
(\%)\end{array}$ & $\begin{array}{l}\text { Duração } \\
\text { (dias) }\end{array}$ & $\begin{array}{c}\text { Peso } \\
(\mathrm{g})\end{array}$ & $\begin{array}{l}\text { Viabilidade } \\
\text { pupal } \\
(\%)\end{array}$ & & & \\
\hline Testemunha $\left({ }^{1}\right)$ & $27,5 \mathrm{a}^{2}$ & $86,7 \mathrm{ab}$ & $7,3 \mathrm{c}$ & $0,2 \mathrm{a}$ & $97,5 a$ & $34,7 \mathrm{a}$ & $84,4 a b$ & $5,2 \mathrm{ab}$ \\
\hline SP79-1011 & $26,5 \mathrm{ab}$ & $83,0 \mathrm{ab}$ & $7,5 \mathrm{bc}$ & $0,2 \mathrm{a}$ & $90,8 \mathrm{a}$ & $34,0 \mathrm{ab}$ & $75,5 \mathrm{ab}$ & $5,5 \mathrm{ab}$ \\
\hline RB867515 & $25,8 b$ & $88,0 \mathrm{ab}$ & $7,8 \mathrm{ab}$ & $0,2 \mathrm{a}$ & $90,1 \mathrm{a}$ & $33,5 b$ & $79,0 \mathrm{ab}$ & $5,3 a b$ \\
\hline RB855453 & $26,0 \mathrm{~b}$ & $91,5 \mathrm{ab}$ & $7,5 \mathrm{bc}$ & $0,2 \mathrm{a}$ & $91,6 a$ & $33,5 b$ & $84,0 \mathrm{ab}$ & $5,3 a b$ \\
\hline CTC 15 & $26,0 \mathrm{~b}$ & $95,8 \mathrm{a}$ & $7,4 \mathrm{bc}$ & $0,2 \mathrm{a}$ & $94,5 \mathrm{a}$ & $33,4 b$ & $90,8 \mathrm{a}$ & $4,9 b$ \\
\hline SP80-1842 & $26,3 \mathrm{ab}$ & $90,6 \mathrm{ab}$ & $7,6 a b c$ & $0,2 \mathrm{a}$ & $94,6 \mathrm{a}$ & $33,9 \mathrm{ab}$ & $85,6 a b$ & $5,3 \mathrm{ab}$ \\
\hline SP89-1115 & $26,1 b$ & $87,00 \mathrm{ab}$ & $7,8 \mathrm{ab}$ & $0,2 \mathrm{a}$ & $93,2 \mathrm{a}$ & $33,9 \mathrm{ab}$ & $81,5 \mathrm{ab}$ & $5,7 \mathrm{a}$ \\
\hline СТC 9 & $26,5 \mathrm{ab}$ & $91,1 \mathrm{ab}$ & $7,8 \mathrm{ab}$ & $0,2 \mathrm{a}$ & $93,5 \mathrm{a}$ & $34,3 \mathrm{ab}$ & $84,4 \mathrm{ab}$ & $5,5 \mathrm{ab}$ \\
\hline RB855536 & $26,2 \mathrm{ab}$ & $87,8 \mathrm{ab}$ & $7,4 \mathrm{bc}$ & $0,2 \mathrm{a}$ & $90,1 \mathrm{a}$ & $33,6 a b$ & $79,4 \mathrm{ab}$ & $5,2 \mathrm{ab}$ \\
\hline SP81-3250 & $26,1 b$ & $76,7 \mathrm{ab}$ & 7,7abc & $0,2 \mathrm{a}$ & $91,0 \mathrm{a}$ & $33,8 \mathrm{ab}$ & $69,4 b$ & $5,1 \mathrm{ab}$ \\
\hline SP87-365 & $26,4 \mathrm{ab}$ & $75,0 \mathrm{~b}$ & $8,0 \mathrm{a}$ & $0,2 \mathrm{a}$ & $94,8 \mathrm{a}$ & $34,4 \mathrm{ab}$ & $71,0 \mathrm{ab}$ & $5,0 \mathrm{~b}$ \\
\hline $\mathrm{F}$ (Tratamentos) & $2,8^{*}$ & $2,7^{*}$ & $4,4^{*}$ & $1,4^{\text {ns }}$ & $1,1^{\mathrm{ns}}$ & $2,6^{*}$ & $2,3^{*}$ & $2,6^{*}$ \\
\hline C.V. $(\%)$ & 3,1 & 13,1 & 3,8 & 8,1 & 7,5 & 2,2 & 15,3 & 7,7 \\
\hline
\end{tabular}

${ }^{1}$ Dieta padrão (ausência de colmo seco triturado); ${ }^{*}$ significativo pelo teste $\mathrm{F}$ a $5 \%$ de significância; ${ }^{\text {ns }}$ não significativo; ${ }^{2}$ Médias não seguidas de mesma letra nas colunas diferem entre si pelo teste de Tukey a 5\% de significância.

Fonte: Elaboração dos autores.

Notou-se que lagartas alimentadas na cultivar SP87-365 tiveram o maior período pupal $(8,0$ dias) possivelmente atribuído à menor adequação do substrato alimentar quando comparado com o da testemunha que apresentou o menor período (7,3 dias) enquanto as demais cultivares ficaram em posição intermediária (Tabela 1). Resultados próximos foram observados por Costa, Francez e Rigolin-Sá (2010) para a duração desse período que foi de 7,6 dias em estudos usando dieta artificial com o objetivo de avaliar o desempenho de $D$. saccharalis tendo em vista a sua criação massal em laboratório. Boiça Junior et al. (1997) verificaram que a duração do período pupal foi de 9,2 dias quando lagartas de D. saccharalis foram alimentadas em dieta artificial 
contendo colmo seco triturado da cultivar SP 713146 , considerada suscetível à broca da cana e de 1,1 dias quando lagartas foram alimentadas em dieta contendo colmo seco triturado da cultivar SP71-1081, considerada moderadamente resistente a $D$. saccharalis. No que se refere ao peso de pupas e a viabilidade pupal, os resultados não revelaram diferenças significativas entre as cultivares e testemunha, indicando que as mesmas apresentaram desempenho similar (Tabela 1).

Em relação ao período da eclosão da larva à emergência dos adultos, o maior valor foi verificado na testemunha (34,7 dias) sendo que este valor não foi significativamente diferente dos observados nas cultivares SP87-365, CTC 9, SP79-1011, SP891115, SP81-3250 e RB855536, que provocaram uma duração de 34,4 a 33,6 dias, sendo que as cultivares RB867515, RB855453 e CTC15 apresentaram-se como mais adequadas ao desenvolvimento de $D$. saccharalis (Tabela 1). Opostamente, com menores períodos, e provavelmente suscetíveis, encontramse as cultivares CTC 15, RB867515 e RB855453 que provocaram períodos de desenvolvimento com duração de 33,4 a 33,5 dias (Tabela 1). Quanto à viabilidade total de $D$. saccharalis notou-se que a cultivar SP81-3250, quando comparada com a cultivar CTC 15 influenciou negativamente, pois afetou a emergência dos adultos com relação ao número total de larvas (Tabela 1).

A longevidade de adultos de D. saccharalis demonstrou diferenças significativas, sendo mais longevos e com 5,7 dias os que emergiram da cultivar SP89-1115 quando comparado com os das cultivares SP87-365 e CTC 15, que foram os menos longevos, e apresentaram respectivamente, 5,0 e 4, 9 dias (Tabela 1). Os efeitos na longevidade de adultos de $D$. saccharalis presentes nessa cultivar indica uma menor suscetibilidade comparativa a $D$. saccharalis que nas cultivares SP87-365 e CTC 15.

De forma geral, os resultados obtidos para o período da eclosão da larva à emergência dos adultos e a viabilidade total variaram, respectivamente, de 33,4 a 34,7 dias e de 69,4 a $90,8 \%$, enquanto a longevidade de adultos variou de 4,9 a 5,7 dias (Tabela 1). Boiça Junior et al. (2011), obtiveram valores médios de 38,9 dias para o período da eclosão da larva à emergência dos adultos e 63,8 $\%$ para a viabilidade total, sendo a longevidade de adultos de aproximadamente 4,6 dias quando incorporaram colmo seco triturado de cultivares de cana-de-açúcar em dieta artificial. Costa, Francez e Rigolin-Sá (2010) relataram que a longevidade de adultos de $D$. saccharalis é em média de 7,15 dias.

Considerando as condições em que foi realizado o presente estudo, pode-se verificar que a cultivar SP87-365 apresentou menores valores para a viabilidade larval e longevidade de adultos quando comparada com a cultivar CTC 15 (Tabela 1) indicandoumamenoradequação ao desenvolvimento de D. saccharalis. A suscetibilidade da cultivar CTC 15 a D. saccaharalis em relação à dieta padrão foi constatada nos menores valores para o período larval e de eclosão da larva à emergência do adulto.

Para identificar as características biológicas importantes para a discriminação da variabilidade genética entre os tratamentos, excluiu-se o peso de pupas e a viabilidade pupal em que não foram observadas diferenças significativas, evidenciando desempenho similar entre as cultivares e a testemunha (Tabela 1). Dessa forma, das oito características biológicas avaliadas, apenas seis, foram utilizadas para estimar a distância generalizada de Mahalanobis $\left(\mathrm{D}^{2}\right)$ e o agrupamento entre os tratamentos.

Em um dendrograma, grande mudança de nível indica a união de cultivares heterogêneas (BARROSO; ARTES, 2003). Assim, utilizando-se $65 \%$ de similaridade como critério para definição dos grupos, houve formação de quatro grupos (Figura 1). O grupo I foi formado pelas cultivares: RB855453, RB855536, SP79-1011, RB867515, SP80-1842, SP81-3250, SP89-1115 e CTC 9; o grupo II foi formado pela cultivar SP87-365; o grupo 
III pela testemunha; e o grupo IV pela cultivar CTC 15. O coeficiente de correlação cofenética (r) foi de 0,72 , evidenciando a existência de um ajuste regular entre a matriz de dissimilaridade e o dendrograma obtido. Valores de CCC menores que 0,7 indicam a inadequação do método de agrupamento (ROHLF, 1970).

Figura 1. Dendrograma obtido pelo método da ligação média entre grupo (UPGMA) estimado a partir da distância generalizada de Mahalanobis $\left(\mathrm{D}^{2}\right)$ entre a testemunha ${ }^{1}$ e dez cultivares de cana-de-açúcar. Temperatura: $28 \pm 1^{\circ} \mathrm{C}$; Umidade relativa: $80 \pm 10 \%$; Fotofase: 14 horas.

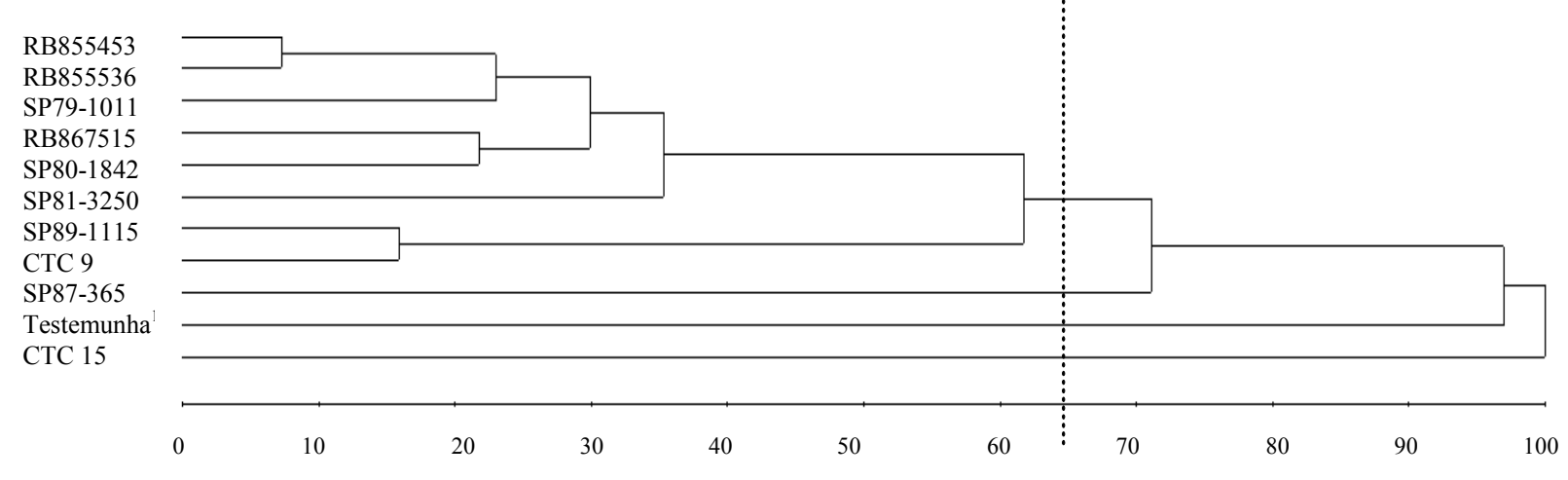

${ }^{1}$ Dieta padrão (ausência de colmo seco triturado). O valor do coeficiente de correlação cofenética (r) é de 0,72 .

Fonte: Elaboração dos autores.

Quando foi efetuado o agrupamento baseado no método de otimização de Tocher (Tabela 2), constatou-se a formação de cinco grupos, sendo estes divergentes com os formados pelo método da ligação média entre grupo (UPGMA). Apesar da diferença observada no número de grupos entre os métodos de agrupamento, de maneira geral, os resultados foram concordantes e contribuíram para a validação das inferências realizadas, sendo possível afirmar que a utilização da análise de comparação de médias, juntamente com as técnicas de agrupamento foram eficientes na discriminação das cultivares de cana-de-açúcar quanto aos graus de resistência a $D$. saccharalis.

Nesse sentido, através do perfil das médias dos grupos para as características biológicas avaliadas (Tabela 3), os resultados demonstraram que as médias diferem e que os grupos são divergentes permitindo classificar as cultivares com exceção do grupo formado pela testemunha em suscetíveis, moderadamente resistente e altamente suscetível a D. saccaharalis.

Portanto, classificadas como suscetíveis e pertencentes ao grupo I encontram-se as cultivares RB855453, RB855536, SP80-1842, SP79-1011, RB867515, SP81-3250, SP89-1115 e CTC 9; a cultivar SP87-365 pertencente ao grupo II pode ser classificada como moderadamente resistente do tipo antibiose; e a cultivar CTC 15 pertencente ao grupo IV como altamente suscetível a $D$. saccharalis (Tabela 3).

Observou-se pela análise de agrupamento (Figura 1 e Tabela 2 e 3) que a testemunha apresentou valores próximos aos observados na cultivar CTC 15 e esta apresentou comportamento distinto das demais cultivares e as técnicas de agrupamento, apontaram essa divergência, pois a 
mesma foi altamente suscetível a $D$. saccharalis, de acordo com os valores encontrados para algumas das características biológicas estudadas.

As técnicas de análise multivariadas utilizadas no presente estudo foram eficientes para a análise da divergência genética entre as cultivares de canade-açúcar. A indicação de cultivares para fins de melhoramento deve ser feita com base no potencial per se e na magnitude de suas dissimilaridades (CRUZ; REGAZZI; CARNEIRO, 2004). Além disso, há tendência de cultivares de cana-de-açúcar de ciclo de maturação precoce, mais ricas em sacarose (DINARDO-MIRANDA, 2008) e menos fibrosas (PINTO; BOTELHO; OLIVEIRA, 2009) serem mais atraídas pela broca da cana.

Tabela 2. Agrupamento pelo método de otimização de Tocher da testemunha $\left({ }^{1}\right)$ e de dez cultivares de cana-de-açúcar com base na distância generalizada de Mahalanobis $\left(\mathrm{D}^{2}\right)$ estimada a partir de seis características biológicas $\left(^{2}\right)$ para resistência a Diatraea saccharalis. Temperatura: $28 \pm 1{ }^{\circ} \mathrm{C}$; Umidade relativa: $80 \pm 10 \%$; Fotofase: 14 horas.

\begin{tabular}{ccl}
\hline Grupo & $\begin{array}{c}\text { Número } \\
\text { de } \\
\text { tratamentos }\end{array}$ & \\
\hline I & 6 & RB855453, RB855536, SP80-1842, SP79-1011, RB867515 e SP81-3250 \\
II & 2 & SP89-1115 e CTC 9 \\
III & 1 & SP87-365 \\
IV & 1 & Testemunha $\left(^{2}\right)$ \\
V & 1 & CTC 15
\end{tabular}

${ }^{1}$ Dieta padrão (ausência de colmo seco triturado); ${ }^{2}$ Viabilidade larval e total, período larval e pupal, período da eclosão da larva à emergência do adulto e longevidade de adultos.

Fonte: Elaboração dos autores.

Tabela 3. Médias obtidas segundo grupos formados pela análise de agrupamento para as características biológicas: período larval (dias), viabilidade larval (\%), período pupal (dias), período da eclosão da larva à emergência do adulto (PELEA) (dias), viabilidade total (\%) e a longevidade dos adultos (dias). Temperatura: $28 \pm 1{ }^{\circ} \mathrm{C}$; Umidade relativa: $80 \pm 10 \%$; Fotofase: 14 horas.

\begin{tabular}{|c|c|c|c|c|c|c|c|}
\hline & Grupo & $\begin{array}{l}\text { Período } \\
\text { larval }\end{array}$ & $\begin{array}{c}\text { Viabilidade } \\
\text { larval }\end{array}$ & $\begin{array}{l}\text { Período } \\
\text { pupal }\end{array}$ & $\begin{array}{l}\text { PELEA } \\
\text { (dias) }\end{array}$ & $\begin{array}{l}\text { Viabilidade } \\
\text { total }\end{array}$ & $\begin{array}{l}\text { Longevidade } \\
\text { (dias) }\end{array}$ \\
\hline I & $\begin{array}{l}\text { RB855453, RB855536, } \text { SP80-1842, } \\
\text { SP79-1011, RB867515, SP81-3250, } \\
\text { SP89-1115 e CTC 9 }\end{array}$ & 26,1 & 87,0 & 7,6 & 33,8 & 80,0 & 5,4 \\
\hline II & SP87-365 & 26,4 & 75,0 & 8,0 & 34,4 & 71,0 & 5,0 \\
\hline III & Testemunha $^{1}$ & 27,5 & 86,7 & 7,30 & 34,7 & 84,4 & 5,2 \\
\hline IV & CTC 15 & 26,0 & 95,8 & 7,4 & 33,4 & 90,8 & 4,9 \\
\hline
\end{tabular}

${ }^{1}$ Dieta padrão (ausência de colmo seco triturado).

Fonte: Elaboração dos autores. 
Nesse caso e diante dos resultados obtidos, a cultivar SP87-365 comportou-se como moderadamente resistente do tipo antibiose a $D$. saccharalis e a mais promissora para ser utilizada em futuros cruzamentos por destacar-se em condições de campo de acordo com a Copersucar (1995) pela alta produtividade, ciclo de maturação de média-tardia e teor de fibra intermediário.

\section{Conclusões}

A cultivar CTC 15 apresentou-se como altamente suscetível a $D$. saccharalis, enquanto a cultivar SP87-365 comportou-se como moderadamente resistente do tipo antibiose a $D$. saccharalis.

\section{Agradecimentos}

À COPERCANA pelas cultivares utilizadas na pesquisa; ao corpo técnico do Laboratório de Controle Biológico da Usina São Martinho pelos insetos e apoio em infraestrutura; e à Coordenação de Aperfeiçoamento de Pessoal de Nível Superior (CAPES) pela concessão da bolsa de estudos à primeira autora.

\section{Referências}

AGRIANUAL. Anuário da agricultura brasileira. São Paulo: Instituto FNP, 2010. 241 p.

ARAÚJO, J. R.; BOTELHO, P. S. M.; ARAÚJO, S. M. S. S.; ALMEIDA, L. C.; DEGASPARI, N. Nova dieta artificial para criação da Diatraea saccharalis (Fabr.). Saccharum, São Paulo, v. 36, n. 2, p. 45-48, 1985.

BARROSO, L. P.; ARTES, R. Análise multivariada. Lavras: UFLA, 2003. $151 \mathrm{p}$.

BOIÇA JÚNIOR, A. L.; LARA, F. M.; BELLODI, M. P. Influência de variedades de cana-de-açúcar, incorporadas em dieta artificial, no desenvolvimento de Diatraea saccharalis (Fabr.) e no seu parasitismo por Cotesia Alavipes (Cam.). Anais da Sociedade Entomológica do Brasil, Piracicaba, v. 26, p. 37-542, 1997.

BOIÇA JUNIOR, A. L.; LEONELO, A. F.; JESUS, F. G. Dietas artificiais incorporadas ou não a colmos triturados de variedades de cana-de-açúcar na biologia de Diatraea saccharalis (F.) (Lepidoptera: Crambidae). Semina: Ciências Agrárias, Londrina, v. 32, n. 1, p. 39-48, 2011.

COPERSUCAR. $5^{a}$ Geração de variedades. Piracicaba: Copersucar, 1995. p. 16-23. (Boletim técnico, n. 2).

COSTA, D. M. da; FRANCEZ, A. C. C.; RIGOLINSÁ, O. Biologia da broca da cana-de-açúcar (Diatraea saccharalis) (Lepidoptera: Crambidae) em dieta artificial. Ciência et Praxis, Belo Horizonte, v. 3, n. 5, p. 13-16, 2010.

CRUZ, C. D. Programa GENES: análise multivariada e simulação. Viçosa: UFV, 2006. 175 p.

CRUZ, C. D.; CARNEIRO, P. C. S. Modelos biométricos aplicados ao melhoramento genético. Viçosa: UFV, $2003.585 \mathrm{p}$.

CRUZ, C. D.; REGAZZI, A. J. Modelos biométricos aplicados ao melhoramento genético. 2. ed. Viçosa, Universidade Federal de Viçosa, 1997. 390 p.

CRUZ, C. D.; REGAZZI, A. J.; CARNEIRO, P. C. S. Modelos biométricos aplicados ao melhoramento genético. Viçosa: UFV, 2004. 480 p.

DEMETRIO, P. A.; ZONETTI, P. C.; MUNHOZ, R. E. F. Avaliação de clones de cana-de-açúcar promissores RB's quanto à resistência à broca-da-cana (Diatraea saccharalis) na região noroeste do Paraná. Cesumar, Maringá, v. 10, n. 1, p. 13-16, 2008.

DINARDO-MIRANDA, L. L. Fitossanidade: Pragas. In: DINARDO-MIRANDA, L. L.; VASCONCELOS, A. C. M.; LANDELL, M. G. A. (Ed.). Cana-de-açúcar. Campinas: Instituto Agronômico, 2008. p. 349-403.

EMPRESA BRASILEIRA DE PESQUISA AGROPECUÁRIA - EMBRAPA. Centro Nacional de Pesquisa de Solos Sistema brasileiro de classificação de solos. Brasília: Embrapa. Produção de informação, Embrapa Solos, 1999. 412 p.

GALLO, D.; NAKANO, O.; SILVEIRA NETO, S.; CARVALHO, R. P. L.; BATISTA, G. C.; BERTI FILHO, E.; PARRA, J. R. P.; ZUCHI, R. A.; ALVES, S. B.; VENDRAMIM, J. D.; MARCHINI, L. C.; LOPES, J.R.S.; OMOTO, C. Manual de entomologia agrícola. Piracicaba: FEALQ, 2002. 920 p.

HENSLEY, S. D.; HAMMOND, A. H. Laboratory techniques for rearing the sugar cane borer on an artificial diet. Journal of Economic Entomology.Lanham, v. 61, n. 6, p. 1742-1743, 1968.

LARA, F. M. Princípios de resistência de plantas aos insetos. 2. ed. São Paulo: Ícone, 1991. 336 p. 
MACEDO, N.; ARAÚJO, J. R. Efeitos da queima do canavial sobre insetos predadores. Anais da Sociedade Entomológica do Brasil, Londrina, v. 29, n. 1, p. 71-77, 2000.

PINTO, A. S.; BOTELHO, P. S. M.; OLIVEIRA, H. N. Guia ilustrativo de pragas e insetos benéficos da canade-açúcar. Piracicaba: Livroceres, 2009. 160 p.

ROHLF, F. J. Adaptive hierarchical clustering schemes. Systematic Zoology, Reino Unido, v. 18, n. 1, p. 58-82, 1970.

ROSSETTO, R.; DIAS, F. L. F.; VITTI, A. C. Nutrição e adubação: fertilidade de solo, nutrição e adubação. In: DINARDO-MIRANDA, L. L.; VASCONCELOS, A. C. M.; LANDELL, M. G. A. (Ed.). Cana-de-açúcar. Campinas: Instituto Agronômico, 2008. p. 221-238.

SCAGLIA, M.; CHAUD-NETTO, J.; BROCHETTOBRAGA, M. R.; CEREGATO, S. A.; GOBBI, N.; RODRIGUES, A. Oviposition sequence and offspring of mated and virgin females of Cotesia flavipes
(Hymenoptera: Braconidae) parasitizing Diatraea saccharalis larvae (Lepidoptera: Crambidae). Journal of Venomous Animals and Toxins Including Tropical Diseases, Botucatu, v. 11, n. 3, p. 283-298, 2005.

SILVEIRA, L. C. P.; VENDRAMIM, J. D.; ROSSETTO, C. J. Efeito de genótipos de milho no desenvolvimento de Spodoptera frugiperda (J.E. Smith). Anais da Sociedade Entomológica do Brasil, Londrina, v. 26, n. 2, p. 291298, 1997.

WHITE, W. H. Movement and establishment of sugarcane borer (Lepidoptera: Pyralidae) larvae on resistant and susceptible sugarcane. The Florida Entomologist, Flórida, v. 76, n. 3, p. 465-473, 1993.

XAVIER, M. A.; MENDONÇA, J. R.; SANGUINO, A. Viveiros de mudas. In: DINARDO-MIRANDA, L. L.; VASCONCELOS, A. C. M.; LANDELL, M. G. A. (Ed.). Cana-de-açúcar. Campinas: Instituto Agronômico, 2008. p. 535-546. 